Article

\title{
Forced Zika Virus Infection of Culex pipiens Leads to Limited Virus Accumulation in Mosquito Saliva
}

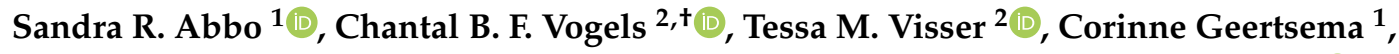 \\ Monique M. van Oers ${ }^{1}$, Constantianus J. M. Koenraadt ${ }^{2}$ and Gorben P. Pijlman ${ }^{1, *(D)}$ \\ 1 Laboratory of Virology, Wageningen University \& Research, Droevendaalsesteeg 1, \\ 6708 PB Wageningen, The Netherlands; sandra.abbo@wur.nl (S.R.A.); corinne.geertsema@wur.nl (C.G.); \\ monique.vanoers@wur.nl (M.M.v.O.) \\ 2 Laboratory of Entomology, Wageningen University \& Research, Droevendaalsesteeg 1, \\ 6708 PB Wageningen, The Netherlands; chantal.vogels@yale.edu (C.B.F.V.); tessa.visser@wur.nl (T.M.V.); \\ sander.koenraadt@wur.nl (C.J.M.K.) \\ * Correspondence: gorben.pijlman@wur.nl \\ + Current address: Epidemiology of Microbial Diseases, Yale School of Public Health, 60 College Street, \\ New Haven, CT 06510, USA.
}

Received: 19 May 2020; Accepted: 16 June 2020; Published: 19 June 2020

\begin{abstract}
Zika virus (ZIKV) is a mosquito-borne pathogen that caused a large outbreak in the Americas in 2015 and 2016. The virus is currently present in tropical areas around the globe and can cause severe disease in humans, including Guillain-Barré syndrome and congenital microcephaly. The tropical yellow fever mosquito, Aedes aegypti, is the main vector in the urban transmission cycles of ZIKV. The discovery of ZIKV in wild-caught Culex mosquitoes and the ability of Culex quinquefasciatus mosquitoes to transmit ZIKV in the laboratory raised the question of whether the common house mosquito Culex pipiens, which is abundantly present in temperate regions in North America, Asia and Europe, could also be involved in ZIKV transmission. In this study, we investigated the vector competence of $C x$. pipiens (biotypes molestus and pipiens) from the Netherlands for ZIKV, using Usutu virus as a control. After an infectious blood meal containing ZIKV, none of the tested mosquitoes accumulated ZIKV in the saliva, although $2 \%$ of the $C x$. pipiens pipiens mosquitoes showed ZIKV-positive bodies. To test the barrier function of the mosquito midgut on virus transmission, ZIKV was forced into $C x$. pipiens mosquitoes by intrathoracic injection, resulting in $74 \%$ (molestus) and 78\% (pipiens) ZIKV-positive bodies. Strikingly, 14\% (molestus) and 7\% (pipiens) of the tested mosquitoes accumulated ZIKV in the saliva after injection. This is the first demonstration of ZIKV accumulation in the saliva of $C x$. pipiens upon forced infection. Nevertheless, a strong midgut barrier restricted virus dissemination in the mosquito after oral exposure and we, therefore, consider $C x$. pipiens as a highly inefficient vector for ZIKV.
\end{abstract}

Keywords: Zika virus; flavivirus; arbovirus; Culex pipiens; vector competence; midgut barrier; the Netherlands

\section{Introduction}

Mosquito-borne viruses are a severe threat to human health [1,2]. Climate change, increased global trade and travel, and the ability of viruses to adapt to new vectors and hosts contribute to the geographic expansion of these mosquito-borne pathogens [1,2]. Zika virus (ZIKV; family Flaviviridae, genus Flavivirus) was first isolated from a caged, sentinel rhesus monkey in the canopy of the Zika forest in Uganda in 1947 [2,3]. In 1948, the virus was discovered in Aedes africanus mosquitoes in the same forest [2,3], and in 1954 the first human ZIKV isolate was obtained from a Nigerian female [2,4]. Much later, the virus re-emerged in Asia and the Pacific islands, and started a large outbreak in humans 
in Brazil in 2015 [2,5,6]. Historically, ZIKV infection results in a mild, self-limiting febrile illness for an estimated $20 \%$ of the infected individuals [7]. However, during the outbreak in the Americas, ZIKV infections in humans unexpectedly caused severe diseases, such as Guillain-Barré syndrome and congenital Zika syndrome including microcephaly $[7,8]$.

The widespread distribution of the yellow fever mosquito, Aedes aegypti, and the Asian tiger mosquito, Aedes albopictus, in Central and South America [9] may have favored the rapid emergence of ZIKV across the Western Hemisphere. Field studies and laboratory vector competence experiments have shown that mosquitoes of the Aedes genus are the main vectors in both the sylvatic and urban transmission cycles of ZIKV [3,10-16]. However, the discovery of ZIKV in field-collected Culex mosquitoes [17-20] and the recent demonstration of experimental ZIKV transmission by Culex quinquefasciatus [21,22] have posed the question of whether the common house mosquito, Culex pipiens, could also be involved in ZIKV transmission. Since $C x$. pipiens mosquitoes are abundantly present in temperate regions in North America, Asia and Europe [23,24], where the ZIKV vectors Ae. aegypti and Ae. albopictus are less dominant [9,25], ZIKV transmission by both Aedes and Culex vectors would greatly increase the human population size at risk for ZIKV infection.

Cx. pipiens can be found in two morphologically indistinguishable biotypes, pipiens and molestus, which differ in behavior, physiology and genetic background. The pipiens biotype prefers to feed on birds, diapauses during winter and requires a blood meal to lay eggs [26]. The molestus biotype prefers to bite mammals, including humans, remains active during winter and does not need a blood meal to lay the first batch of eggs [26]. Cx. pipiens is a competent vector for the flaviviruses West Nile virus (WNV) and Usutu virus (USUV) [24,27-29]. So far, Cx. pipiens has shown to be an incompetent vector for ZIKV during vector competence experiments [30-36], although important positive controls for the competence of the tested mosquitoes and the infectivity of the viruses have not always been included.

The aim of this study was to determine the vector competence of $C x$. pipiens (biotypes molestus and pipiens) from the Netherlands for ZIKV. We investigated whether or not $C x$. pipiens mosquitoes could experimentally transmit ZIKV after an infectious blood meal. We tested high numbers of mosquitoes, and we infected $C x$. pipiens with USUV and Ae. aegypti with ZIKV as positive controls. We also injected ZIKV into the thoraxes of $C x$. pipiens mosquitoes to study the viral replication dynamics and the barrier function of the mosquito midgut on ZIKV transmission.

\section{Materials and Methods}

\subsection{Mosquito Rearing}

Colonies of $C x$. pipiens molestus and Cx. pipiens pipiens from the Netherlands [29] were maintained at $23{ }^{\circ} \mathrm{C}$ with $60 \%$ relative humidity and a 16:8 light:dark period. Mosquitoes were reared as previously described [29]. Egg rafts were placed in trays with tap water and Liquifry No. 1 (Interpet Ltd., Dorking, UK). Emerged larvae were fed daily with TetraMin baby fish food (Tetra, Melle, Germany). Pupae were allowed to emerge in $30 \mathrm{~cm}$ cubic Bugdorm cages, and the adults were provided with a $6 \%$ glucose solution.

Ae. aegypti mosquitoes (Rockefeller strain, obtained from Bayer AG, Monheim, Germany) were maintained as described earlier [37]. Mosquitoes were reared at $27^{\circ} \mathrm{C}$ with $70 \%$ relative humidity and a 12:12 light:dark period. Adult female mosquitoes laid their eggs on moist filter paper that was placed in a cup containing tap water. The eggs were air-dried for 3-4 days and then placed in trays containing tap water with Liquifry No. 1 (Interpet Ltd.). The larvae were fed with TetraMin baby fish food (Tetra). Adults were kept in $30 \mathrm{~cm}$ cubic Bugdorm cages with access to a $6 \%$ glucose solution.

\subsection{Cells and Viruses}

African green monkey kidney Vero E6 cells were grown as a monolayer in Dulbecco's Modified Eagle Medium (DMEM; Gibco, Carlsbad, CA, USA) supplemented with 10\% fetal bovine serum (FBS; Gibco), penicillin (100 U/mL; Sigma-Aldrich, Saint Louis, MO, USA) and streptomycin (100 $\mu \mathrm{g} / \mathrm{mL}$; Sigma-Aldrich) (P/S). The cells were maintained at $37^{\circ} \mathrm{C}$ with $5 \% \mathrm{CO}_{2}$. Prior to virus infections, 
the Vero cells were seeded in HEPES-buffered DMEM medium (Gibco) supplemented with 10\% FBS and P/S. When mosquito body lysate or saliva was added to the cells, the HEPES-buffered DMEM medium was additionally supplemented with gentamycin $(50 \mu \mathrm{g} / \mathrm{mL}$; Gibco) and fungizone $(2.5 \mu \mathrm{g} / \mathrm{mL}$ of amphotericin B and $2.1 \mu \mathrm{g} / \mathrm{mL}$ of sodium deoxycholate; Gibco). This medium will hereafter be named DMEM HEPES complete.

All experiments involving infectious ZIKV and USUV were executed in the biosafety level 3 laboratory of Wageningen University \& Research. Passage 5 and 6 virus stocks of ZIKV, Suriname 2016 (GenBank accession no. KU937936.1; EVAg Ref-SKU 011V-01621; obtained from Erasmus Medical Center, Rotterdam, the Netherlands), and passage 6 virus stocks of USUV, the Netherlands 2016 (GenBank accession no. MH891847.1; EVAg Ref-SKU 011V-02153; obtained from Erasmus Medical Center), were grown on Vero cells. Viral titers, expressed as 50\% tissue culture infectious dose per milliliter $\left(\mathrm{TCID}_{50} / \mathrm{mL}\right.$ ), were measured using end point dilution assays (EPDAs) on Vero cells in 60-well MicroWell plates (Nunc, Roskilde, Denmark).

\subsection{Infectious Blood Meal}

Prior to the infectious blood meal, female mosquitoes were starved for one day. Mosquitoes were then orally exposed to ZIKV or USUV by providing them with infectious blood from a Hemotek PS5 feeder (Discovery Workshops, Lancashire, UK) in a dark room for $1 \mathrm{~h}$. Infectious blood meals were prepared by mixing virus stock with human blood (Sanquin Blood Supply Foundation, Nijmegen, the Netherlands) to obtain a final virus titer of $1.0 \times 10^{7} \mathrm{TCID}_{50} / \mathrm{mL}$. C $x$. pipiens molestus and $C x$. pipiens pipiens received ZIKV during four and three independent experiments, respectively. As positive controls, Ae. aegypti was infected with ZIKV to test the quality of the virus stock, and Cx. pipiens molestus and $C x$. pipiens pipiens were exposed to USUV to test the competence of the mosquitoes. After the blood meal, the mosquitoes were anesthetized using $\mathrm{CO}_{2}$, and fully engorged females were selected. A small number of engorged females was collected in individual SafeSeal micro tubes (Sarstedt, Nümbrecht, Germany) containing $0.5 \mathrm{~mm}$ zirconium oxide beads (Next Advance, Averill Park, NY, USA) to determine the virus titer in the mosquito body directly after engorgement. All other females were incubated at $28{ }^{\circ} \mathrm{C}$ with access to $6 \%$ glucose.

\subsection{Intrathoracic Injection}

Female mosquitoes were immobilized with $\mathrm{CO}_{2}$ prior to intrathoracic injection using a Drummond Nanoject II Auto-Nanoliter Injector (Drummond Scientific, Broomall, PA, USA). Cx. pipiens molestus was injected with $1.0 \times 10^{4} \mathrm{TCID}_{50}$ of ZIKV or $3.5 \times 10^{3} \mathrm{TCID}_{50}$ of USUV (positive control). C $x$. pipiens pipiens was injected with decreasing doses of ZIKV containing $1.0 \times 10^{4}, 1.0 \times 10^{2}$ or $3.0 \times 10^{1} \mathrm{TCID}_{50}$, or with $3.5 \times 10^{3} \mathrm{TCID}_{50}$ of USUV (positive control). Ae. aegypti was injected with $1.0 \times 10^{4} \mathrm{TCID}_{50}$ of ZIKV (positive control). The injected mosquitoes were incubated at $28{ }^{\circ} \mathrm{C}$ with access to $6 \%$ glucose.

\subsection{Salivation Assay}

Fourteen days post infection, the mosquitoes were immobilized with $\mathrm{CO}_{2}$ and the legs and wings of each mosquito were removed. Next, mosquito saliva was collected by inserting the mosquito proboscis into a $200 \mu \mathrm{L}$ pipet tip containing $5 \mu \mathrm{L}$ of a $50 \%$ FBS and $25 \%$ sugar solution in sterilized tap water. After $45 \mathrm{~min}$, the mosquito bodies were stored at $-80{ }^{\circ} \mathrm{C}$ in individual SafeSeal micro tubes (Sarstedt) containing $0.5 \mathrm{~mm}$ zirconium oxide beads (Next Advance). Individual mosquito saliva samples were mixed with $55 \mu \mathrm{L}$ DMEM HEPES complete and stored at $-80^{\circ} \mathrm{C}$.

\subsection{Infectivity Assay}

Frozen mosquito body samples were homogenized in a Bullet Blender Storm (Next Advance) at maximum speed for $2 \mathrm{~min}$. The body homogenates were centrifuged in an Eppendorf 5424 centrifuge at 14,500 rpm for $1 \mathrm{~min}$. Next, $100 \mu \mathrm{L}$ of DMEM HEPES complete was added to each body homogenate. The homogenates in medium were blended again at maximum speed for $2 \mathrm{~min}$, and centrifuged at 
$14,500 \mathrm{rpm}$ for $2 \mathrm{~min}$. Thirty $\mu \mathrm{L}$ of each mosquito body or saliva sample was then added to one well of a 96-well plate containing a monolayer of Vero cells in DMEM HEPES complete. After $2 \mathrm{~h}$ at $37^{\circ} \mathrm{C}$, the medium of the cells was replaced by $100 \mu \mathrm{L}$ fresh DMEM HEPES complete. Six days post infection, the wells were scored virus-positive or -negative based on cytopathic effect (CPE). The number of virus-positive mosquito bodies or salivas was expressed as a percentage of the total number of mosquitoes tested. Viral titers in $\mathrm{TCID}_{50} / \mathrm{mL}$ were measured for mosquito bodies and salivas using EPDAs on Vero cells. After 6 days, the wells were scored virus-positive or -negative based on CPE.

\subsection{RNA Extraction and Reverse Transcriptase PCR}

Total RNA was isolated from Vero cells using TRIzol reagent (Invitrogen, Carlsbad, CA, USA) according to the manufacturer's protocol. RNA yields were measured using a NanoDrop ND-1000 spectrophotometer. Reverse transcriptase PCR (RT-PCR) was done using a 2720 Thermal Cycler (Applied Biosystems, Foster City, CA, USA) and the SuperScript III One-Step RT-PCR System with Platinum Taq DNA polymerase (Invitrogen), according to the manufacturer's protocol. Per RT-PCR reaction, $100 \mathrm{ng}$ of total RNA was added. Primers targeting the region encoding ZIKV non-structural protein 1 (NS1) (forward: 5'-GAGACGAGATGCGGTACAGG-3'; reverse: $5^{\prime}$-CGACCGTCAGTTGAACTCCA-3') and the region coding for USUV non-structural protein 5 (NS5) (forward: 5'-GGCTGTAGAGGACCCTCGG-3'; reverse: 5'-GACTGCCTTTCGCTTTGCCA-3') were used at annealing temperatures of $55^{\circ} \mathrm{C}$ and $60^{\circ} \mathrm{C}$, respectively.

\subsection{Mosquito Wing Length Measurement}

The right wings of 20 female $C x$. pipiens molestus, $C x$. pipiens pipiens and Ae. aegypti were removed and mounted on sticky tape on a slide. The wing length was measured from the end of the alula to the top of the wing, excluding the fringe scales, using ImageFocus software (Euromex Microscopes, Arnhem, the Netherlands) calibrated with a slide graticule of $0.01 \mathrm{~mm}$. The wing length measurements were used as an estimate of body size, as wing length is known to be correlated with body mass [38].

\subsection{Statistical Analysis}

The Kolmogorov-Smirnov test was used to determine whether mosquito wing lengths and viral titers of engorged mosquitoes were normally distributed. Differences in wing lengths and differences in viral titers were then tested for significance using an unpaired, two-tailed $t$-test. All statistical tests were performed using GraphPad Prism 5 (GraphPad Software, San Diego, CA, USA).

\section{Results}

\subsection{No ZIKV Transmission by Cx. pipiens after an Infectious Blood Meal}

To assess the vector competence of $C x$. pipiens molestus and $C x$. pipiens pipiens for ZIKV, the mosquitoes were offered an infectious blood meal containing $1.0 \times 10^{7} \mathrm{TCID}_{50} / \mathrm{mL}$ of ZIKV. As positive controls, Ae. aegypti and both $C x$. pipiens biotypes were infected with $1.0 \times 10^{7} \mathrm{TCID}_{50} / \mathrm{mL}$ of ZIKV or USUV, respectively. To investigate the variability in engorgement among individual mosquitoes, viral body titers were determined for a selection of mosquitoes directly after ingestion of an infectious blood meal (Figure 1A,B). Cx. pipiens mosquitoes, blood fed with ZIKV or USUV, showed very similar median viral titers ranging from $4.6 \times 10^{5}$ to $6.3 \times 10^{5} \mathrm{TCID} \mathrm{D}_{50} / \mathrm{mL}$. Ae. aegypti mosquitoes blood fed with ZIKV showed significantly lower viral titers compared to the $C x$. pipiens biotypes blood fed with ZIKV $(p<0.05)$. This can be explained by the fact that the Ae. aegypti mosquitoes were smaller in size than the $C x$. pipiens mosquitoes. The Ae. aegypti mosquitoes showed an average wing length ( \pm standard deviation) of $2.60 \mathrm{~mm}( \pm 0.18 \mathrm{~mm})$, whereas average wing lengths of $3.34 \mathrm{~mm}( \pm 0.32 \mathrm{~mm})$ and $3.65 \mathrm{~mm}( \pm 0.24 \mathrm{~mm})$ were measured for molestus and pipiens, respectively. The measured wing lengths of $A$ e. aegypti were significantly lower compared to the wing lengths of each $C x$. pipiens biotype 
$(p<0.0001)$. The smaller size of Ae. aegypti mosquitoes likely results in a lower volume of ingested blood containing virus.
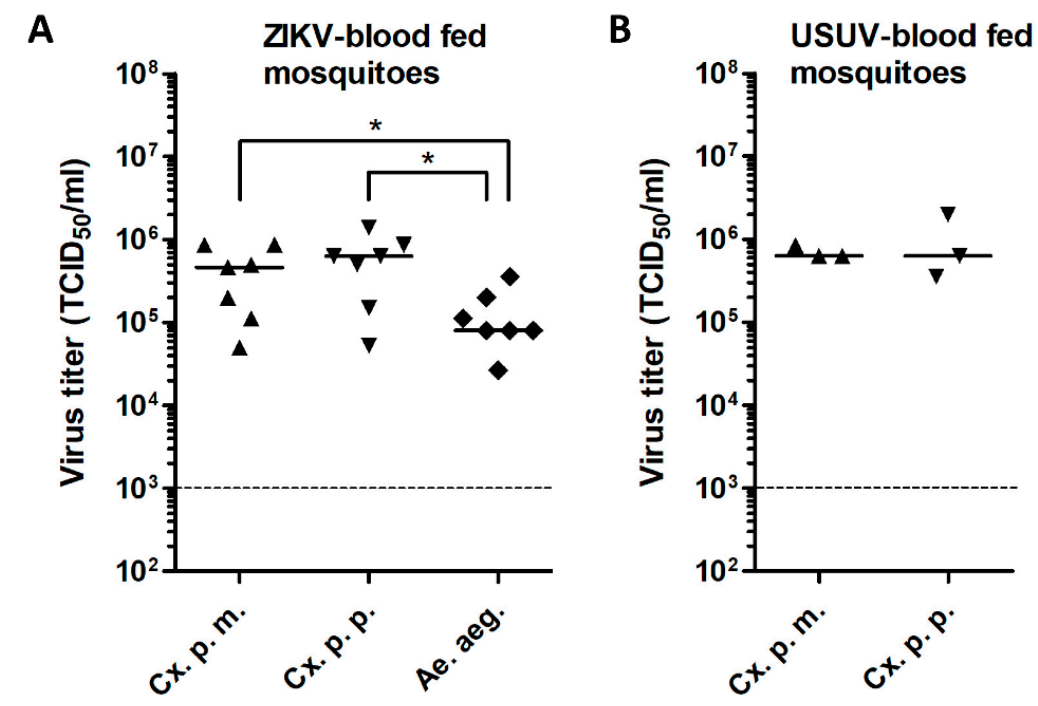

Figure 1. Virus titers in engorged Cx. pipiens molestus (Cx. p. m.), Cx. pipiens pipiens (Cx. p. p.), and Ae. aegypti (Ae. aeg.) mosquitoes immediately after ingestion of a blood meal containing (A) ZIKV or (B) USUV. Data points show individual mosquitoes exposed to ZIKV or USUV. Lines show median virus titers. Dashed lines indicate the detection limit of the EPDA. Asterisks indicate a significant difference $(p<0.05, t$-test).

After the infectious blood meal, all other engorged mosquitoes were incubated at $28^{\circ} \mathrm{C}$ for 14 days, and afterwards the mosquito bodies and salivas were tested for the presence of virus using infectivity assays on Vero cells. The presence of virus was scored based on CPE, and the presence of viral RNA was also confirmed using RT-PCR for a subset of the results. None of the 55 tested $C x$. pipiens molestus mosquitoes showed a ZIKV-positive body or saliva (Figure 2A,B). Out of the $133 \mathrm{C}$. pipiens pipiens tested, two mosquitoes showed a ZIKV-positive body but no positive saliva (Figure 2A,B). For ZIKV-blood fed Ae. aegypti mosquitoes, which served as positive controls, $100 \%$ of the tested mosquitoes were infected and $65 \%$ showed virus-positive saliva (Figure 2A,B), which corresponds with our previous work [37]. In addition, the USUV-blood fed Cx. pipiens showed 67\% (molestus) and $88 \%$ (pipiens) virus-positive bodies (Figure $2 \mathrm{~A}$ ), and 31\% (molestus) and $21 \%$ (pipiens) virus-positive salivas (Figure 2B), demonstrating that both $C x$. pipiens biotypes were competent vectors for USUV. Given that none of the $C x$. pipiens mosquitoes accumulated ZIKV in the saliva after oral infection, we conclude that $C x$. pipiens is a highly inefficient vector for ZIKV. 
A

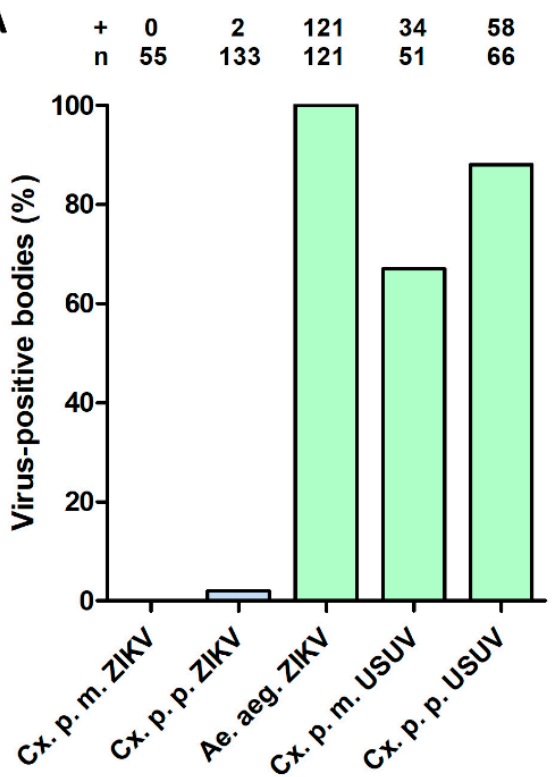

B

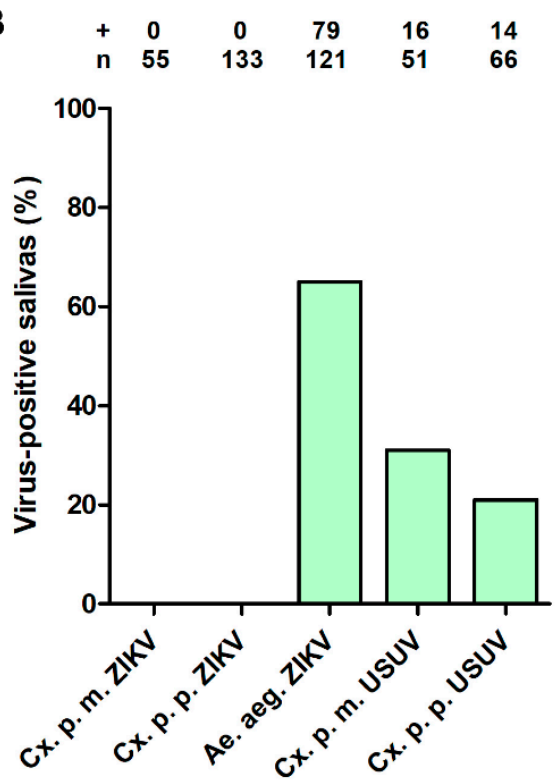

Figure 2. (A) Infection and (B) transmission of ZIKV and USUV after oral exposure to $C x$. pipiens molestus (Cx. p. m.), Cx. pipiens pipiens (Cx. p. p.) and Ae. aegypti (Ae. aeg.). After the infectious blood meal, mosquitoes were incubated at $28^{\circ} \mathrm{C}$ for 14 days. The number of virus-positive mosquito bodies or salivas (indicated by + ) is expressed as a percentage of the total number of mosquitoes tested (indicated by $n$ ). Experimental groups are depicted in blue; positive controls are depicted in green.

\subsection{Low ZIKV Titers in Cx. pipiens after an Infectious Blood Meal}

Viral titers of virus-positive bodies and salivas were measured by EPDAs. The two ZIKV-positive Cx. pipiens pipiens bodies both had a viral titer of $6.3 \times 10^{3} \mathrm{TCID}_{50} / \mathrm{mL}$ (Figure $3 \mathrm{~A}$ ), whereas the viral body titers of Ae. aegypti mosquitoes were very high with a median titer of $1.1 \times 10^{7} \mathrm{TCID}_{50} / \mathrm{mL}$ (Figure 3B). The median viral saliva titer of Ae. aegypti was below the detection limit of $1.0 \times 10^{3}$ $\mathrm{TCID}_{50} / \mathrm{mL}$ (Figure 3B). For USUV-blood fed Cx. pipiens, the median viral body titers were $8.0 \times 10^{4}$ $\mathrm{TCID}_{50} / \mathrm{mL}$ (molestus) and $2.9 \times 10^{5} \mathrm{TCID}_{50} / \mathrm{mL}$ (pipiens), and the median viral saliva titers were below the detection limit of $1.0 \times 10^{3} \mathrm{TCID}_{50} / \mathrm{mL}$ (molestus) and $6.3 \times 10^{3} \mathrm{TCID}_{50} / \mathrm{mL}$ (pipiens) (Figure $3 \mathrm{C}, \mathrm{D}$ ). These results showed that ZIKV had the ability to infect $C x$. pipiens and replicate in the mosquito with very low efficiency. 
A

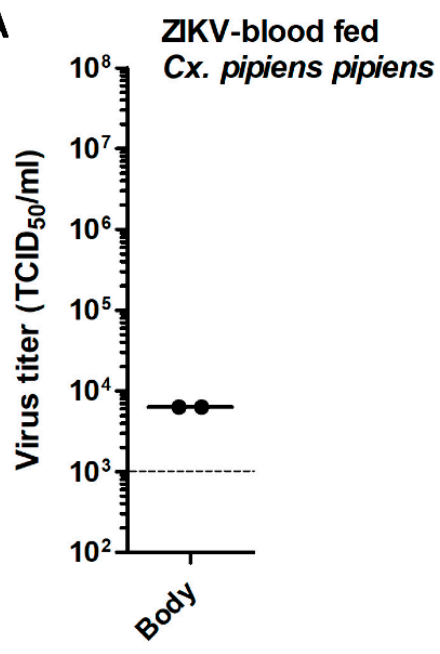

C

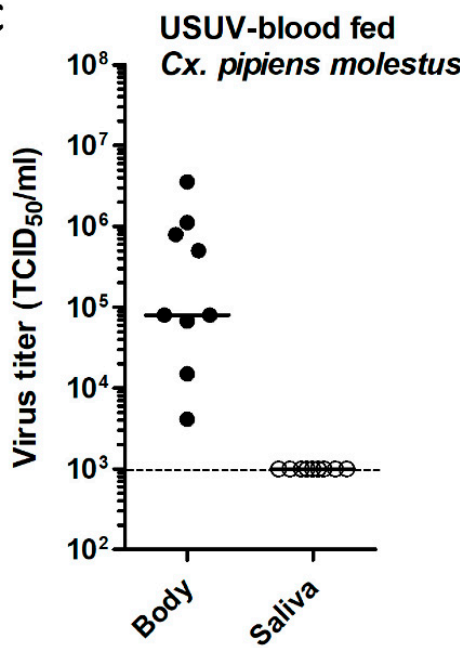

B

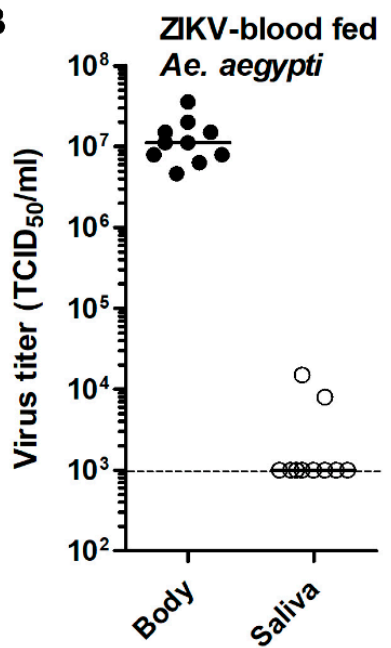

D

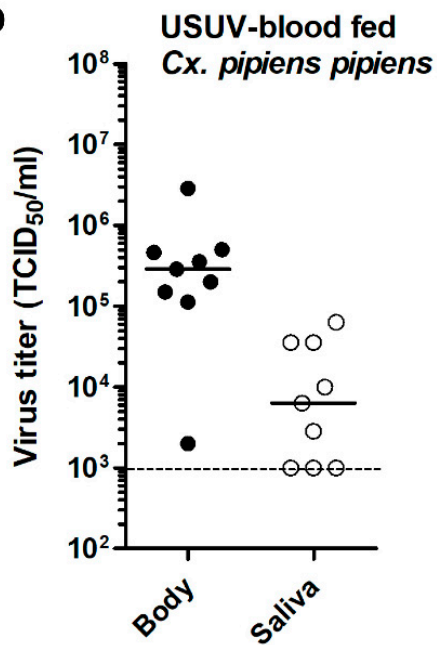

Figure 3. Virus titers in bodies and salivas of $C x$. pipiens molestus, $C x$. pipiens pipiens, and Ae. aegypti mosquitoes after oral exposure to ZIKV or USUV. After oral exposure, mosquitoes were incubated at $28^{\circ} \mathrm{C}$ for 14 days. Virus titers were determined by EPDA for (A) bodies of ZIKV-blood fed Cx. pipiens pipiens, (B) bodies and salivas of ZIKV-blood fed Ae. aegypti, (C) bodies and salivas of USUV-blood fed Cx. pipiens molestus, (D) bodies and salivas of USUV-blood fed Cx. pipiens pipiens. Data points show individual mosquitoes infected with ZIKV or USUV. Lines show median virus titers. Dashed lines indicate the detection limit of the EPDA.

3.3. Intrathoracic ZIKV Injection Leads to Virus Replication in Cx. pipiens with Limited Dissemination to the Mosquito Saliva

To investigate whether ZIKV was unable to pass the mosquito midgut barrier in $C x$. pipiens, mosquitoes were injected in the thorax with $1.0 \times 10^{4} \mathrm{TCID}_{50}$ of ZIKV. As positive controls, Ae. aegypti was injected with ZIKV and both $C x$. pipiens biotypes were injected with USUV. After 14 days at $28^{\circ} \mathrm{C}$, mosquito bodies and salivas were analyzed for the presence of virus. During infectivity assays, the presence of virus was scored based on CPE and, for a subset of the results, these scores were also confirmed by RT-PCR. High percentages (74\% for molestus and 78\% for pipiens) of the injected mosquitoes had ZIKV-positive bodies (Figure 4A). Interestingly, 14\% (molestus) and 7\% (pipiens) of the injected mosquitoes also showed infectious ZIKV in their saliva (Figure 4B). After injection of Ae. aegypti with ZIKV, which served as a positive control experiment, $100 \%$ of the injected mosquitoes showed virus-positive bodies (Figure $4 \mathrm{~A}$ ), whereas $72 \%$ of the injected mosquitoes showed virus-positive saliva (Figure 4B), which is in line with our earlier results [37]. As another positive control, both 
biotypes of $C x$. pipiens were injected with USUV, which showed that $100 \%$ of the tested $C x$. pipiens molestus and Cx. pipiens pipiens had USUV-positive bodies (Figure 4A), and 94\% (molestus) and 88\% (pipiens) of the injected mosquitoes had USUV-positive saliva (Figure 4B). This indicates that virus dissemination to the saliva in Cx. pipiens is more efficient with USUV than with ZIKV.

A

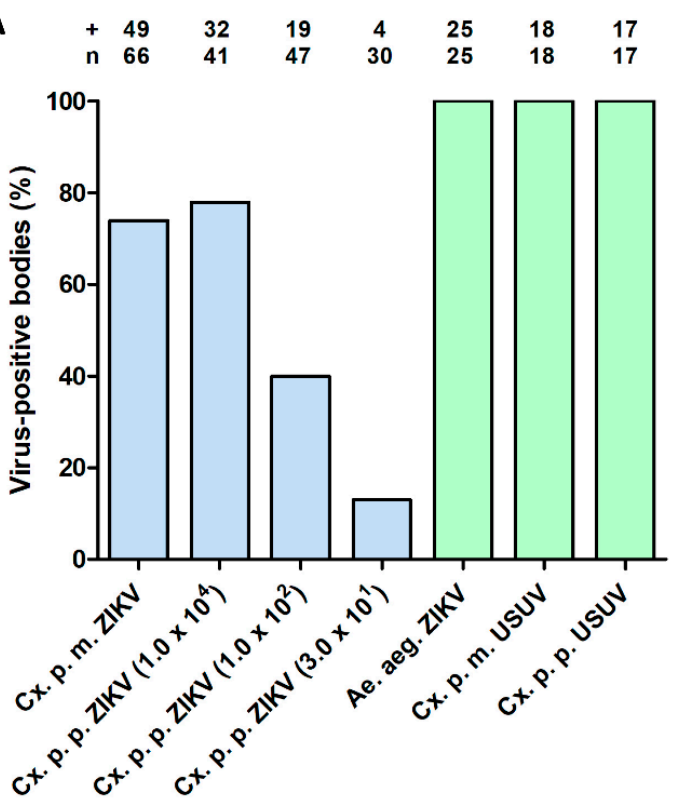

B

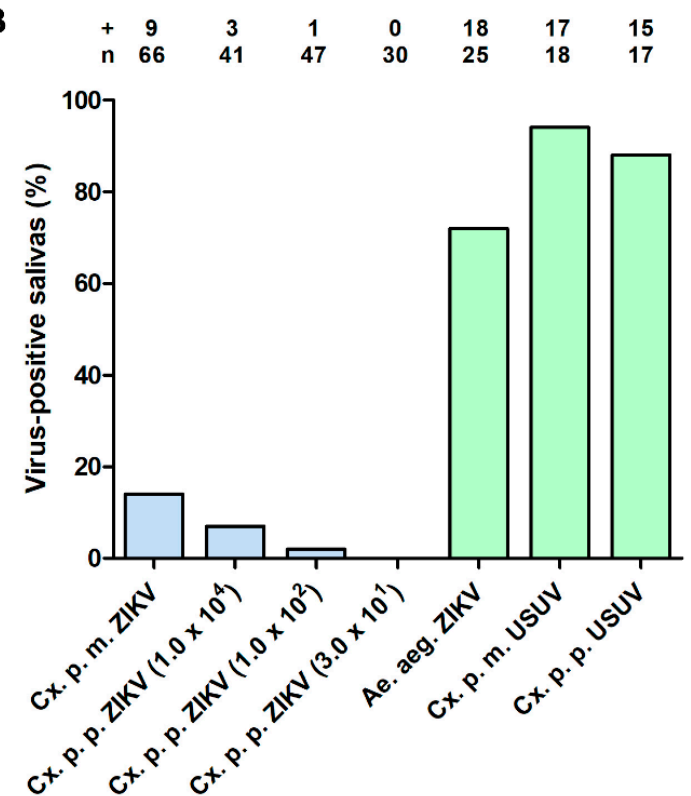

Figure 4. (A) Infection and (B) transmission of ZIKV and USUV after intrathoracic injection in $C x$. pipiens molestus (Cx. p. m.), Cx. pipiens pipiens (Cx. p. p.) and Ae. aegypti (Ae. aeg.). Cx. pipiens pipiens mosquitoes were injected with three different ZIKV doses, as indicated (in TCID 50 ). The injected mosquitoes were incubated at $28{ }^{\circ} \mathrm{C}$ for 14 days. The number of virus-positive mosquito bodies or salivas (indicated by + ) is expressed as a percentage of the total number of mosquitoes tested (indicated by $n$ ). Experimental groups are depicted in blue; positive controls are depicted in green.

\subsection{Effect of Injected Viral Dose on ZIKV Infection of Cx. pipiens}

To investigate whether the percentage of ZIKV-positive mosquitoes after intrathoracic injection was affected by the viral dose provided, $C x$. pipiens pipiens mosquitoes were also injected with lower doses of ZIKV. After 14 days, $40 \%$ of the $C x$. pipiens pipiens mosquitoes injected with $1.0 \times 10^{2} \mathrm{TCID}_{50}$ of ZIKV showed virus-positive bodies, whereas $2 \%$ showed virus-positive salivas (Figure 4A,B). Additionally, when a viral dose of $3.0 \times 10^{1} \mathrm{TCID}_{50}$ was supplied, $13 \%$ of the tested $C x$. pipiens pipiens mosquitoes showed virus-positive bodies, whereas none of the mosquitoes showed virus-positive saliva (Figure 4A,B). This indicated that the infection and transmission potential of ZIKV-injected $C x$. pipiens pipiens was dependent on the viral dose provided, but also that a low ZIKV dose of $3.0 \times 10^{1}$ $\mathrm{TCID}_{50}$ can infect a mosquito.

\subsection{Variability of Viral Titers in ZIKV-Injected Cx. pipiens}

To obtain better insight into the ZIKV replication dynamics in injected $C x$. pipiens mosquitoes, viral body and saliva titers were measured by EPDAs. To validate ZIKV replication in the primary ZIKV vector Ae. aegypti (positive control), the bodies and salivas of ZIKV-injected Ae. aegypti were also titrated. ZIKV body titers in $C x$. pipiens injected with a dose of $1.0 \times 10^{4} \mathrm{TCID}_{50}$ were highly variable with maximum titers of $1.1 \times 10^{6} \mathrm{TCID}_{50} / \mathrm{mL}$ (molestus) and $6.3 \times 10^{5} \mathrm{TCID}_{50} / \mathrm{mL}$ (pipiens) (Figure 5A,B). This showed that ZIKV is intrinsically capable of replication to high viral titers in $C x$. pipiens. The median viral body titers of ZIKV-injected $C x$. pipiens were $9.6 \times 10^{3} \mathrm{TCID}_{50} / \mathrm{mL}$ for pipiens and below the detection limit of $1.0 \times 10^{3} \mathrm{TCID}_{50} / \mathrm{mL}$ for molestus. For Ae. aegypti, a high median viral body titer of $6.32 \times 10^{6} \mathrm{TCID}_{50} / \mathrm{mL}$ was found (Figure $5 \mathrm{C}$ ). 
A

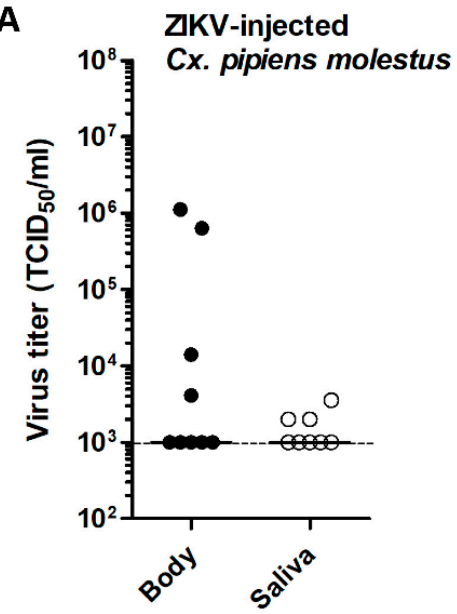

B

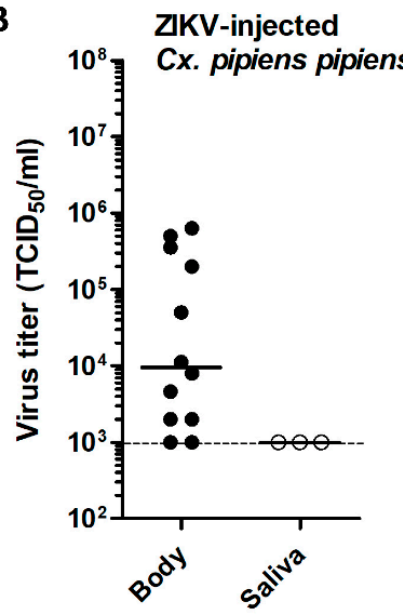

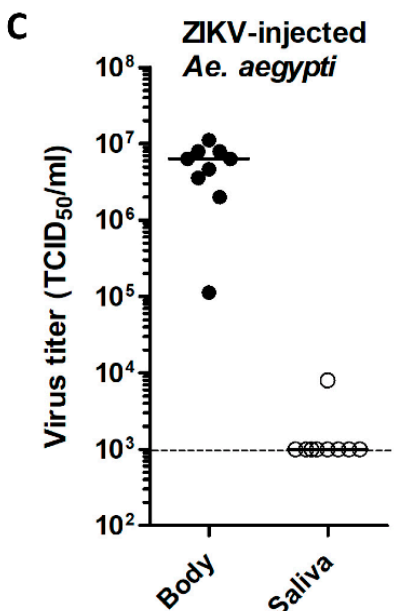

Figure 5. Virus titers in bodies and salivas of $C x$. pipiens molestus, $C x$. pipiens pipiens, and Ae. aegypti mosquitoes after intrathoracic injection with ZIKV. After injection, mosquitoes were incubated at $28{ }^{\circ} \mathrm{C}$ for 14 days. Virus titers of the bodies and salivas were determined by EPDA for (A) ZIKV-injected $C x$. pipiens molestus, (B) ZIKV-injected Cx. pipiens pipiens (injection dose: $1.0 \times 10^{4} \mathrm{TCID}_{50}$ ), (C) ZIKV-injected Ae. aegypti. Data points show individual mosquitoes infected with ZIKV. Lines show median virus titers. Dashed lines indicate the detection limit of the EPDA.

Interestingly, four $C x$. pipiens molestus mosquitoes with ZIKV-positive saliva showed viral body titers below the detection limit of $1.0 \times 10^{3} \mathrm{TCID}_{50} / \mathrm{mL}$ (Figure $5 \mathrm{~A}$ ). Moreover, out of the three ZIKV-injected $C x$. pipiens pipiens mosquitoes with ZIKV-positive saliva, two mosquitoes had relatively high viral body titers of $3.6 \times 10^{5} \mathrm{TCID}_{50} / \mathrm{mL}$ and $5.0 \times 10^{5} \mathrm{TCID}_{50} / \mathrm{mL}$, whereas the third mosquito had a relatively low viral body titer of $8.0 \times 10^{3} \mathrm{TCID}_{50} / \mathrm{mL}$ (Figure $5 \mathrm{~B}$ ). This indicates that viral dissemination into the saliva of $C x$. pipiens does not always correlate with a high viral titer in the mosquito body.

\section{Discussion}

In this study, we set out to determine the vector competence of Dutch $C x$. pipiens (biotypes molestus and pipiens) for ZIKV and we found that $C x$. pipiens was unable to experimentally transmit ZIKV after an infectious blood meal. However, to the best of our knowledge, our study is the first study to demonstrate ZIKV dissemination to the saliva of $C x$. pipiens mosquitoes after intrathoracic injection. Previous studies reported the presence of ZIKV in Cx. pipiens bodies [30,31] and heads [30] after injection but no virus accumulation in the saliva [30,31]. This suggests that ZIKV is incapable of infecting the salivary glands and/or of entering the saliva of $C x$. pipiens [31]. We showed, however, that ZIKV can accumulate in the mosquito saliva after an intrathoracic injection with a viral dose as low as $1.0 \times 10^{2} \mathrm{TCID}_{50}$. This viral dose for injection is similar or lower compared to other studies that did not report ZIKV presence in the saliva [30,31]. Based on our results, we conclude that ZIKV is intrinsically capable of dissemination to the saliva of $C x$. pipiens upon forced infection.

Nonetheless, even after forced infection, ZIKV replication in $C x$. pipiens appeared to be suboptimal, as $74 \%$ (molestus) and $78 \%$ (pipiens) of the $C x$. pipiens injected with a viral dose of $1.0 \times 10^{4} \mathrm{TCID}_{50}$ of ZIKV showed virus-positive bodies compared to $100 \%$ of the ZIKV-injected Ae. aegypti and USUV-injected $C x$. pipiens. These results suggest a general replication deficiency of ZIKV in Culex cells, which has also been observed by others [31]. The underlying mechanisms responsible for the specific restriction of ZIKV in $C x$. pipiens are currently unknown and need further investigation. Important factors that should be considered are physical barriers at the mosquito midgut and salivary glands, mosquito host factors required for virus replication, mosquito immune responses and the mosquito midgut microbiome [39]. Flaviviruses, such as ZIKV, but also yellow fever virus and dengue virus, are primarily associated with Aedes vectors [40,41]. Other flaviviruses, such as WNV and USUV, 
are mainly associated with Culex vectors [40,41]. Genetic differences between the mosquito genera and/or between the respective flaviviruses likely constrain and maintain the observed vector specificity. However, arboviruses have previously been shown to have the potential to quickly adapt to new vectors $[42,43]$ and, therefore, it is important to investigate the molecular basis underlying the vector specificity of ZIKV, and also to investigate whether virus evolutionary trajectories can be predicted that could potentially lead to new epidemic variants of ZIKV with altered vector specificity.

We provided evidence via injection experiments that the mosquito midgut acted as an important barrier against ZIKV dissemination in $C x$. pipiens. Our finding, with regard to the inability of $C x$. pipiens to transmit ZIKV, is in line with other recent studies suggesting that mosquitoes of the Culex genus are poor ZIKV vectors [30-36,44]. Even at an incubation temperature as high as $28^{\circ} \mathrm{C}, \mathrm{Cx}$. pipiens did not accumulate ZIKV in the saliva after oral exposure [30,31,34]. However, when considering the massive number of mosquitoes in the field and the fact that our laboratory study only measures vector competence and does not take into account all factors contributing to the vectorial capacity of the $C x$. pipiens mosquito species [39], we cannot completely rule out the possibility of ZIKV transmission by $C x$. pipiens in the field. Nevertheless, the reports of others [30-36] and our experiments with high numbers of tested $C x$. pipiens mosquitoes and positive controls to validate the competence of the tested $C x$. pipiens colonies, and the used ZIKV isolate, consolidate the conclusion that $C x$. pipiens is a highly inefficient vector for ZIKV.

Author Contributions: Conceptualization, S.R.A., C.J.M.K. and G.P.P.; methodology, S.R.A., C.B.F.V., T.M.V. and C.G.; validation, S.R.A.; formal analysis, S.R.A.; investigation, S.R.A., C.B.F.V., T.M.V. and C.G.; resources, M.M.v.O., C.J.M.K. and G.P.P.; data curation, S.R.A.; writing-original draft preparation, S.R.A.; writing-review and editing, S.R.A., C.B.F.V., T.M.V., M.M.v.O., C.J.M.K. and G.P.P.; visualization, S.R.A.; supervision, M.M.v.O., C.J.M.K. and G.P.P.; project administration, S.R.A. and G.P.P.; funding acquisition, M.M.v.O., C.J.M.K. and G.P.P. All authors have read and agreed to the published version of the manuscript.

Funding: This research was funded by ZonMW under grant number 522003001 (project: ZikaRisk "Risk of Zika virus introductions for the Netherlands") and by the European Union's Horizon 2020 Research and Innovation Programme under grant number 734548 (project: ZIKAlliance).

Acknowledgments: The authors thank Marleen Abma-Henkens and Giel Göertz for their assistance during the mosquito experiments; Haidong Wang and Jelke Fros for advice about statistical analysis; Pieter Rouweler and other members of the insect rearing group from the Laboratory of Entomology from Wageningen University \& Research for providing mosquitoes; Chantal Reusken for providing the Zika virus Suriname 2016 and Usutu virus the Netherlands 2016 isolates; Barry Rockx and Marion Koopmans for their continued interest in the project.

Conflicts of Interest: The authors declare no conflict of interest. The funders had no role in the design of the study; in the collection, analyses or interpretation of data; in the writing of the manuscript or in the decision to publish the results.

\section{References}

1. Weaver, S.C.; Charlier, C.; Vasilakis, N.; Lecuit, M. Zika, Chikungunya, and Other Emerging Vector-Borne Viral Diseases. Annu. Rev. Med. 2018, 69, 395-408. [CrossRef] [PubMed]

2. Musso, D.; Gubler, D.J. Zika Virus. Clin. Microbiol. Rev. 2016, 29, 487-524. [CrossRef] [PubMed]

3. Dick, G.W.; Kitchen, S.F.; Haddow, A.J. Zika virus. I. Isolations and serological specificity. Trans. R. Soc. Trop. Med. Hyg. 1952, 46, 509-520. [CrossRef]

4. MacNamara, F.N. Zika virus: A report on three cases of human infection during an epidemic of jaundice in Nigeria. Trans. R. Soc. Trop. Med. Hyg. 1954, 48, 139-145. [CrossRef]

5. Zanluca, C.; Melo, V.C.; Mosimann, A.L.; Santos, G.I.; Santos, C.N.; Luz, K. First report of autochthonous transmission of Zika virus in Brazil. Mem. Inst. Oswaldo. Cruz. 2015, 110, 569-572. [CrossRef] [PubMed]

6. Campos, G.S.; Bandeira, A.C.; Sardi, S.I. Zika Virus Outbreak, Bahia, Brazil. Emerg. Infect. Dis. 2015, 21, 1885-1886. [CrossRef]

7. Miner, J.J.; Diamond, M.S. Zika Virus Pathogenesis and Tissue Tropism. Cell Host Microbe. 2017, 21, $134-142$. [CrossRef]

8. Moore, C.A.; Staples, J.E.; Dobyns, W.B.; Pessoa, A.; Ventura, C.V.; Fonseca, E.B.; Ribeiro, E.M.; Ventura, L.O.; Neto, N.N.; Arena, J.F.; et al. Characterizing the Pattern of Anomalies in Congenital Zika Syndrome for Pediatric Clinicians. JAMA Pediatr. 2017, 171, 288-295. [CrossRef] 
9. Kraemer, M.U.; Sinka, M.E.; Duda, K.A.; Mylne, A.Q.; Shearer, F.M.; Barker, C.M.; Moore, C.G.; Carvalho, R.G.; Coelho, G.E.; Van Bortel, W.; et al. The global distribution of the arbovirus vectors Aedes aegypti and Ae. albopictus. Elife 2015, 4, e08347. [CrossRef]

10. Haddow, A.J.; Williams, M.C.; Woodall, J.P.; Simpson, D.I.; Goma, L.K. Twelve Isolations of Zika Virus from Aedes (Stegomyia) Africanus (Theobald) Taken in and above a Uganda Forest. Bull. World Health Organ. 1964, 31, 57-69.

11. Marchette, N.J.; Garcia, R.; Rudnick, A. Isolation of Zika virus from Aedes aegypti mosquitoes in Malaysia. Am. J. Trop. Med. Hyg. 1969, 18, 411-415. [CrossRef]

12. Ferreira-de-Brito, A.; Ribeiro, I.P.; Miranda, R.M.; Fernandes, R.S.; Campos, S.S.; Silva, K.A.; Castro, M.G.; Bonaldo, M.C.; Brasil, P.; Lourenco-de-Oliveira, R. First detection of natural infection of Aedes aegypti with Zika virus in Brazil and throughout South America. Mem. Inst. Oswaldo. Cruz. 2016, 111, 655-658. [CrossRef] [PubMed]

13. Guerbois, M.; Fernandez-Salas, I.; Azar, S.R.; Danis-Lozano, R.; Alpuche-Aranda, C.M.; Leal, G.; Garcia-Malo, I.R.; Diaz-Gonzalez, E.E.; Casas-Martinez, M.; Rossi, S.L.; et al. Outbreak of Zika Virus Infection, Chiapas State, Mexico, 2015, and First Confirmed Transmission by Aedes aegypti Mosquitoes in the Americas. J. Infect. Dis. 2016, 214, 1349-1356. [CrossRef] [PubMed]

14. Ledermann, J.P.; Guillaumot, L.; Yug, L.; Saweyog, S.C.; Tided, M.; Machieng, P.; Pretrick, M.; Marfel, M.; Griggs, A.; Bel, M.; et al. Aedes hensilli as a potential vector of Chikungunya and Zika viruses. PLoS Negl. Trop. Dis. 2014, 8, e3188.

15. Chouin-Carneiro, T.; Vega-Rua, A.; Vazeille, M.; Yebakima, A.; Girod, R.; Goindin, D.; Dupont-Rouzeyrol, M.; Lourenco-de-Oliveira, R.; Failloux, A.B. Differential Susceptibilities of Aedes aegypti and Aedes albopictus from the Americas to Zika Virus. PLoS Negl. Trop. Dis. 2016, 10, e0004543. [CrossRef]

16. Gendernalik, A.; Weger-Lucarelli, J.; Garcia Luna, S.M.; Fauver, J.R.; Ruckert, C.; Murrieta, R.A.; Bergren, N.; Samaras, D.; Nguyen, C.; Kading, R.C.; et al. American Aedes vexans Mosquitoes are Competent Vectors of Zika Virus. Am. J. Trop. Med. Hyg. 2017, 96, 1338-1340. [CrossRef]

17. Diallo, D.; Sall, A.A.; Diagne, C.T.; Faye, O.; Faye, O.; Ba, Y.; Hanley, K.A.; Buenemann, M.; Weaver, S.C.; Diallo, M. Zika virus emergence in mosquitoes in southeastern Senegal, 2011. PLoS ONE 2014, 9, e109442. [CrossRef]

18. Elizondo-Quiroga, D.; Medina-Sanchez, A.; Sanchez-Gonzalez, J.M.; Eckert, K.A.; Villalobos-Sanchez, E.; Navarro-Zuniga, A.R.; Sanchez-Tejeda, G.; Correa-Morales, F.; Gonzalez-Acosta, C.; Arias, C.F.; et al. Zika Virus in Salivary Glands of Five Different Species of Wild-Caught Mosquitoes from Mexico. Sci. Rep. 2018, 8, 809. [CrossRef]

19. Fu, S.; Song, S.; Liu, H.; Li, Y.; Li, X.; Gao, X.; Xu, Z.; Liu, G.; Wang, D.; Tian, Z.; et al. ZIKA virus isolated from mosquitoes: A field and laboratory investigation in China, 2016. Sci. China Life Sci. 2017, 60, 1364-1371. [CrossRef]

20. Guedes, D.R.; Paiva, M.H.; Donato, M.M.; Barbosa, P.P.; Krokovsky, L.; Rocha, S.; Saraiva, K.; Crespo, M.M.; Rezende, T.M.; Wallau, G.L.; et al. Zika virus replication in the mosquito Culex quinquefasciatus in Brazil. Emerg. Microbes. Infect. 2017, 6, e69. [CrossRef]

21. Guo, X.X.; Li, C.X.; Deng, Y.Q.; Xing, D.; Liu, Q.M.; Wu, Q.; Sun, A.J.; Dong, Y.D.; Cao, W.C.; Qin, C.F.; et al. Culex pipiens quinquefasciatus: A potential vector to transmit Zika virus. Emerg. Microbes. Infect. 2016, 5, e102.

22. Smartt, C.T.; Shin, D.; Kang, S.; Tabachnick, W.J. Culex quinquefasciatus (Diptera: Culicidae) From Florida Transmitted Zika Virus. Front. Microbiol. 2018, 9, 768. [CrossRef] [PubMed]

23. Farajollahi, A.; Fonseca, D.M.; Kramer, L.D.; Marm Kilpatrick, A. "Bird biting" mosquitoes and human disease: A review of the role of Culex pipiens complex mosquitoes in epidemiology. Infect. Genet. Evol. 2011, 11, 1577-1585. [CrossRef] [PubMed]

24. Ciota, A.T.; Kramer, L.D. Vector-virus interactions and transmission dynamics of West Nile virus. Viruses 2013, 5, 3021-3047. [CrossRef] [PubMed]

25. Alaniz, A.J.; Carvajal, M.A.; Bacigalupo, A.; Cattan, P.E. Global spatial assessment of Aedes aegypti and Culex quinquefasciatus: A scenario of Zika virus exposure. Epidemiol. Infect. 2018, 147, 1-11. [CrossRef]

26. Byrne, K.; Nichols, R.A. Culex pipiens in London Underground tunnels: Differentiation between surface and subterranean populations. Heredity 1999, 82, 7-15. [CrossRef] 
27. Fros, J.J.; Geertsema, C.; Vogels, C.B.; Roosjen, P.P.; Failloux, A.B.; Vlak, J.M.; Koenraadt, C.J.; Takken, W.; Pijlman, G.P. West Nile Virus: High Transmission Rate in North-Western European Mosquitoes Indicates Its Epidemic Potential and Warrants Increased Surveillance. PLoS Negl. Trop. Dis. 2015, 9, e0003956. [CrossRef]

28. Fros, J.J.; Miesen, P.; Vogels, C.B.; Gaibani, P.; Sambri, V.; Martina, B.E.; Koenraadt, C.J.; van Rij, R.P.; Vlak, J.M.; Takken, W.; et al. Comparative Usutu and West Nile virus transmission potential by local Culex pipiens mosquitoes in north-western Europe. One Health 2015, 1, 31-36. [CrossRef]

29. Vogels, C.B.; Fros, J.J.; Goertz, G.P.; Pijlman, G.P.; Koenraadt, C.J. Vector competence of northern European Culex pipiens biotypes and hybrids for West Nile virus is differentially affected by temperature. Parasit. Vectors 2016, 9, 393. [CrossRef]

30. Amraoui, F.; Atyame-Nten, C.; Vega-Rua, A.; Lourenco-de-Oliveira, R.; Vazeille, M.; Failloux, A.B. Culex mosquitoes are experimentally unable to transmit Zika virus. Euro. Surveill. 2016, 21, 30333. [CrossRef]

31. Kenney, J.L.; Romo, H.; Duggal, N.K.; Tzeng, W.P.; Burkhalter, K.L.; Brault, A.C.; Savage, H.M. Transmission Incompetence of Culex quinquefasciatus and Culex pipiens pipiens from North America for Zika Virus. Am. J. Trop. Med. Hyg. 2017, 96, 1235-1240. [CrossRef] [PubMed]

32. Boccolini, D.; Toma, L.; Di Luca, M.; Severini, F.; Romi, R.; Remoli, M.E.; Sabbatucci, M.; Venturi, G.; Rezza, G.; Fortuna, C. Experimental investigation of the susceptibility of Italian Culex pipiens mosquitoes to Zika virus infection. Euro. Surveill. 2016, 21, 30328. [CrossRef]

33. Aliota, M.T.; Peinado, S.A.; Osorio, J.E.; Bartholomay, L.C. Culex pipiens and Aedes triseriatus Mosquito Susceptibility to Zika Virus. Emerg. Infect. Dis. 2016, 22, 1857-1859. [CrossRef] [PubMed]

34. Weger-Lucarelli, J.; Ruckert, C.; Chotiwan, N.; Nguyen, C.; Garcia Luna, S.M.; Fauver, J.R.; Foy, B.D.; Perera, R.; Black, W.C.; Kading, R.C.; et al. Vector Competence of American Mosquitoes for Three Strains of Zika Virus. PLoS Negl. Trop. Dis. 2016, 10, e0005101. [CrossRef]

35. Heitmann, A.; Jansen, S.; Luhken, R.; Leggewie, M.; Badusche, M.; Pluskota, B.; Becker, N.; Vapalahti, O.; Schmidt-Chanasit, J.; Tannich, E. Experimental transmission of Zika virus by mosquitoes from central Europe. Euro. Surveill. 2017, 22, 30437. [CrossRef] [PubMed]

36. Huang, Y.J.; Ayers, V.B.; Lyons, A.C.; Unlu, I.; Alto, B.W.; Cohnstaedt, L.W.; Higgs, S.; Vanlandingham, D.L. Culex Species Mosquitoes and Zika Virus. Vector Borne Zoonotic Dis. 2016, 16, 673-676. [CrossRef] [PubMed]

37. Goertz, G.P.; Vogels, C.B.F.; Geertsema, C.; Koenraadt, C.J.M.; Pijlman, G.P. Mosquito co-infection with Zika and chikungunya virus allows simultaneous transmission without affecting vector competence of Aedes aegypti. PLoS Negl. Trop. Dis. 2017, 11, e0005654. [CrossRef]

38. Armbruster, P.; Hutchinson, R.A. Pupal mass and wing length as indicators of fecundity in Aedes albopictus and Aedes geniculatus (Diptera: Culicidae). J. Med. Entomol. 2002, 39, 699-704. [CrossRef]

39. Vogels, C.B.; Goertz, G.P.; Pijlman, G.P.; Koenraadt, C.J. Vector competence of European mosquitoes for West Nile virus. Emerg. Microbes. Infect. 2017, 6, e96. [CrossRef]

40. Gaunt, M.W.; Sall, A.A.; de Lamballerie, X.; Falconar, A.K.; Dzhivanian, T.I.; Gould, E.A. Phylogenetic relationships of flaviviruses correlate with their epidemiology, disease association and biogeography. J. Gen. Virol. 2001, 82, 1867-1876. [CrossRef]

41. Grard, G.; Moureau, G.; Charrel, R.N.; Holmes, E.C.; Gould, E.A.; de Lamballerie, X. Genomics and evolution of Aedes-borne flaviviruses. J. Gen. Virol. 2010, 91, 87-94. [CrossRef] [PubMed]

42. Tsetsarkin, K.A.; Vanlandingham, D.L.; McGee, C.E.; Higgs, S. A single mutation in chikungunya virus affects vector specificity and epidemic potential. PLoS Pathog. 2007, 3, e201. [CrossRef] [PubMed]

43. Stapleford, K.A.; Coffey, L.L.; Lay, S.; Borderia, A.V.; Duong, V.; Isakov, O.; Rozen-Gagnon, K.; Arias-Goeta, C.; Blanc, H.; Beaucourt, S.; et al. Emergence and transmission of arbovirus evolutionary intermediates with epidemic potential. Cell Host Microbe. 2014, 15, 706-716. [CrossRef] [PubMed]

44. Lourenco-de-Oliveira, R.; Marques, J.T.; Sreenu, V.B.; Atyame Nten, C.; Aguiar, E.; Varjak, M.; Kohl, A.; Failloux, A.B. Culex quinquefasciatus mosquitoes do not support replication of Zika virus. J. Gen. Virol. 2018, 99, 258-264. [CrossRef] [PubMed]

(C) 2020 by the authors. Licensee MDPI, Basel, Switzerland. This article is an open access article distributed under the terms and conditions of the Creative Commons Attribution (CC BY) license (http://creativecommons.org/licenses/by/4.0/). 